\title{
Investigation of 3D models acquired with UAV oblique images
}

\author{
Hasan Bilgehan Makineci ${ }^{*}$ (D), Lütfiye Karasaka*1(D) \\ ${ }^{1}$ Konya Technical University, Faculty of Engineering and Nature Sciences, Department of Geomatics Engineering, Konya, Turkey
}

\author{
Keywords \\ ANAFI \\ UAV \\ Oblique Image Acquisition \\ 3D Model
}

\begin{abstract}
The concept of oblique image acquisition entered the literature long after the overhead photogrammetric acquisition techniques. The oblique image acquisition technique is applied to model the edge surfaces of buildings that cannot be obtained with vertical (nadir) image acquisition and eliminate the problems that arise in the orthorectification of high-rise buildings in urban areas. Oblique image acquisition by Unmanned Aerial Vehicles (UAV) independent of aerial photogrammetry is considered possible with unique flight plans. How convenient oblique image acquisition with the help of UAVs is and how it affects the final product is a popular topic studied by researchers. In this study, oblique image acquisition was performed using a rotary-wing UAV (Parrot ANAFI) whose camera can move $180^{\circ}$. With the help of the $3 \mathrm{D}$ models obtained, the building was drawn in vector and evaluated to scale. As a result, it has been understood that almost all structural deficiencies in the final products can be eliminated by oblique images. However, it has been revealed that there is still a need for other methods for structures that do not have patterns, such as flat walls.
\end{abstract}

\section{INTRODUCTION}

The digital photogrammetry technique has been developing at a breathtaking movement since the 21st century when it was truly effective. Many factors such as the increase in the success of the GNSS technique in field works (in terms of Ground Sampling Distance -GSD-accuracy), the increase in the efficiency of flight planning software, the completion of pre-flight and post-flight processes in a quicker time, and the acceleration experienced in image acquisition systems have a part in this development (Yastikli and Özerdem, 2017). Despite all the development in this technique, frame-based aerial cameras are not considered sufficient in orthophoto map production in urban areas. Due to the nearby settlement of the building structures or the increase in very high-rise buildings in urban areas, problems arise in image acquisitions made from the nadir direction (vertical acquisition). Oblique image acquisition cameras introduced to solve this problem reveal actual results.

Aerial photogrammetry, which saves time and cost in large-scale map making (such as 1/1000 or $1 / 5000)$, is not considered economical at the same level in very large-scale map works (such as 1/50 or 1/100). Today, Unmanned Aerial Vehicles (UAVs) are seen as the most crucial alternative in studies that can take a very long time with terrestrial methods, in very large-scale map production, in 3D modeling studies, and in almost all studies where humans may be under threat (Uysal et al., 2015). It is a technique used as another option for image acquisition with oblique aerial cameras (Erdönmez, 2018). Oblique image acquisition with UAV under certain conditions is essential to obtain acceptable results (Rossi et al., 2017; Vacca et al., 2017). However, sometimes using a single method in 3D modeling of an object/building may not be sufficient to reach a solution or meet expectations. For example, when creating a 3D model of a building, building facades can usually be modeled with close-up photogrammetry or terrestrial laser scanning method.

In contrast, the aerial photogrammetry method can provide the necessary perspective for building roofs (Aicardi et al., 2016). In such cases, where a single process is not sufficient for 3D modeling studies, it is necessary to solve it by combining the data obtained from different platforms and 
measurement methods. Today, UAV and Terrestrial Laser Scanner (TLS) methods are used in the documentation of buildings, historical artifacts, and archaeological sites in engineering applications (Achille et al., 2015; Toprak et al., 2019; Tuncer et al., 2018; Jo and Hong, 2019; Valenti and Paternò, 2019; Zeybek and Kaya, 2020).

Since it is challenging to use integrated cameras directly for oblique image acquire (it can be done with tilt motors only), it is possible to obtain accurate results in tilted images with the UAV only by paying attention to the fundamental issues in flight planning. It is a significant problem to determine the angle at which the camera will take the image and in which position it will record the image. This study aims to present acceptable and high-accuracy 3D models with oblique-angle images using accurate flight planning techniques. As for the purpose-oriented goals, it can be said that the acquisition, balancing, and modeling of oblique images without any problems. As a result, it is aimed to investigate the contribution and suitability of oblique images to the 3D model creation.

\section{MATERIAL AND METHOD}

In the study, Parrot ANAFI, a rotary-wing UAV with a compact RGB camera, whose camera can move $180^{\circ}$, was used. Meliha Ercan Patient Guesthouse, located in the Selçuk University Campus area, has been determined as the study area. Pix4Dcapture was preferred as flight planning software. With Dual Grid flight planning, which provides suitable planning conditions for 3D models, image acquisition was also performed at $1.50 \mathrm{~cm} / \mathrm{pix}$ (GSD).

\subsection{UAV Used in This Research}

Parrot ANAFI compact UAV with the integrated camera is in the toy class in terms of weight (including $320 \mathrm{~g}$ battery weight) according to the General Directorate of Civil Aviation (SHGM) UAV Regulations (SHT-UAV). The current SHT-UAV valid in our country are classified as UAVs weighing 500 $\mathrm{g}$ (including) and above. For this reason, it does not require any legal license in terms of use. The manufacturer has documented its integrated camera with a field of view of $70^{\circ}$ and a pixel size of $1.3 \mu \mathrm{m}$. The most defining aspect of this UAV is the $180^{\circ}$ rotation of its integrated camera (Figure 1 ). It is possible to say that this feature is an excellent opportunity to take an oblique image. Anafi camera specifications are as shown in Table 1.

Table 1. Anafi camera (Sony IMX230) specifications (Url-1)

\begin{tabular}{|l|l|l|l|}
\hline $\begin{array}{l}\text { Camera } \\
\text { Type }\end{array}$ & Resolution & $\begin{array}{l}\text { Focal } \\
\text { Lenght }\end{array}$ & Pixel Size \\
\hline $\begin{array}{l}\text { Frame } \\
\text { Based }\end{array}$ & $5344 \times 4016$ pix. & $7.5 \mathrm{~mm}$ & $1.12 \times 1.12 \mu \mathrm{m}$ \\
\hline
\end{tabular}

The last valid regulation used for UAVs in our country, SHT-UAV (as revised on 14 July 2020), divides UAVs into four classes according to their maximum take-off weight. UAVs under $500 \mathrm{~g}$ takeoff weight are not included in the instruction. Although the ANAFI UAV is not included in any UAV class due to its weight under $500 \mathrm{~g}$, it has features that can also be used in photogrammetry and remote sensing studies (Table 1 ).

\subsection{Study Area}

Meliha Ercan Patient Guesthouse, which began its activities on May 17, 2018, is located on a total area of $4109 \mathrm{~m}^{2}$. The guesthouse, situated in the Selçuk University Campus Area, is close to the border wall on the rear and side facades, as seen in Figure 2. Because of this closeness, images taken from the nadir direction with the UAV are not manageable to 3D modeling.

\subsection{UAV Flight Planning Managed for Oblique Image Acquisition}

UAV image acquisition plan was created with Pix4dcapture free UAV flight planning software. The design of the flight planning as a double-grid mission is because it allows the creation of horizontal and vertical columns. Figure 3 presents flight planning and considerations.

Pix4dcapture software was used to create the flight plan. Images were taken from a flight height of $39 \mathrm{~m}(1.5 \mathrm{~cm} /$ pixel GSD) to create a 3D model of the building. A total of 117 images were taken during this flight, which took 06:52 minutes in total. Seven GCPs were established around the study area before the flight. The coordinates of the GCPs were measured in epochs enduring 10 seconds at one time. Images and GCPs obtained from the field study were transferred to the computer. 


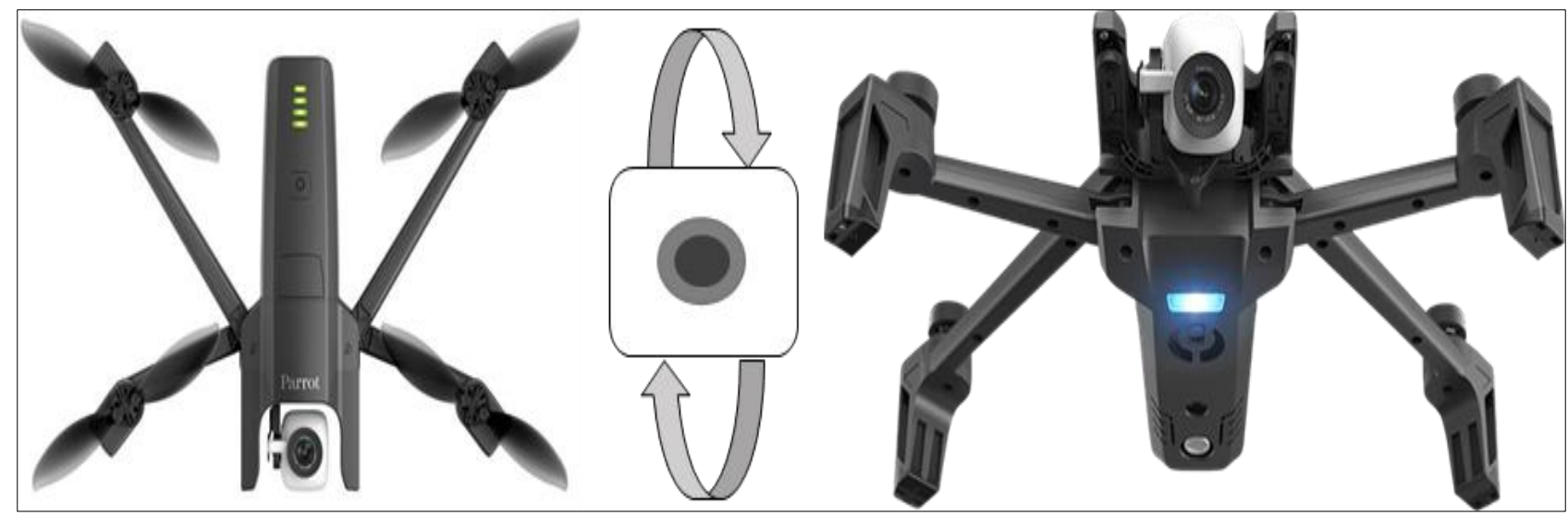

Figure 1. Parrot ANAFI UAV and $180^{\circ}$ rotating integrated camera

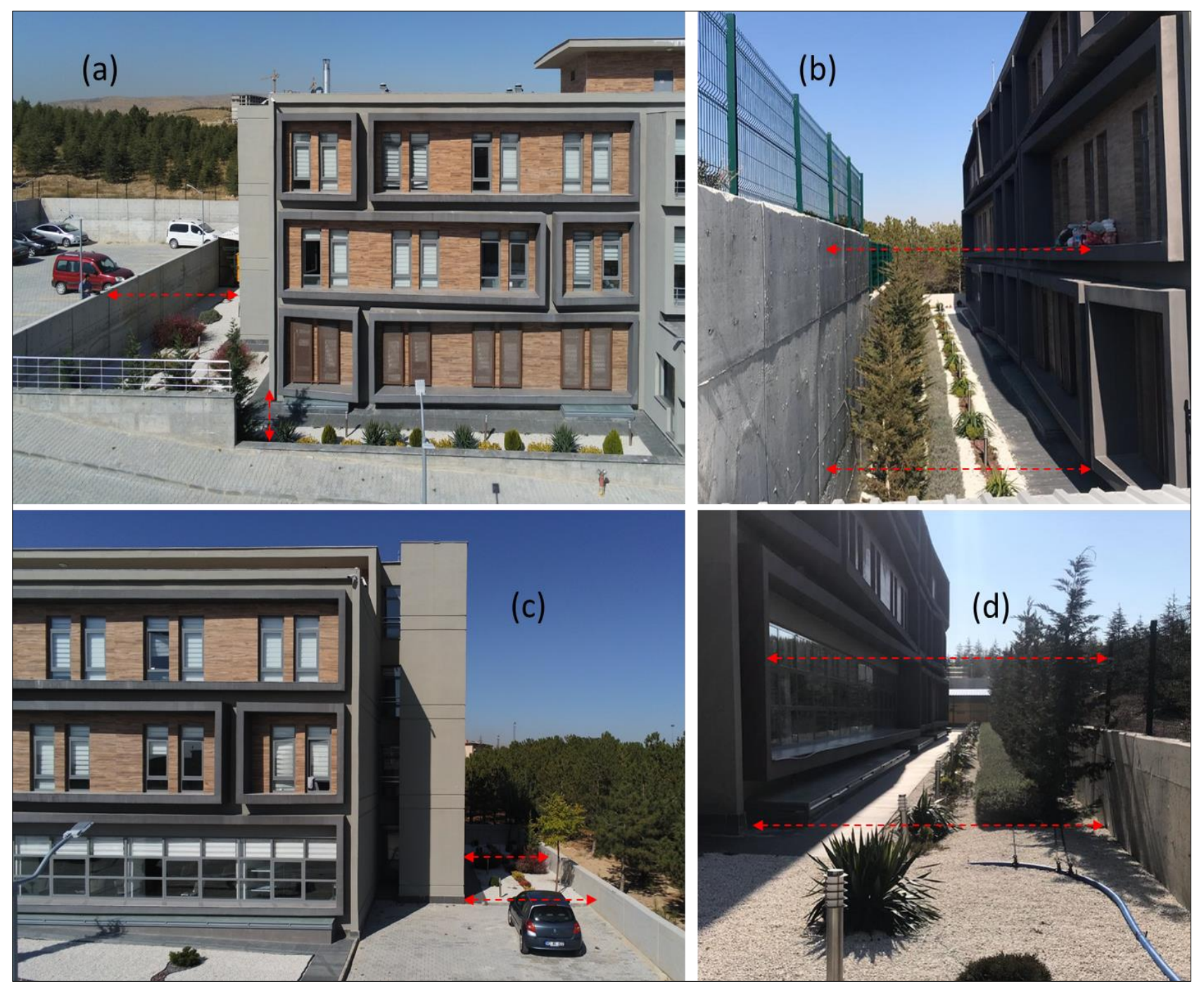

Figure 2. Image of Guesthouse Facades (A-Left Front Facade and Lines Showing Closeness to the Border Wall, BLeft Rear Facade, C- Right Front Facade, D- Right Rear Facade)

Oblique images are taken from an aerial platform (airplane, helicopter, or UAV) with cameras at a unique angle of $35^{\circ}$ to $45^{\circ}$ from a nadir angle. Oblique images allow you to see every facade of buildings and structures that cannot be seen in aerial images taken from a nadir angle, showing blind points (Halıcı and Aydın, 2019; Kun and Güler, 2019). 


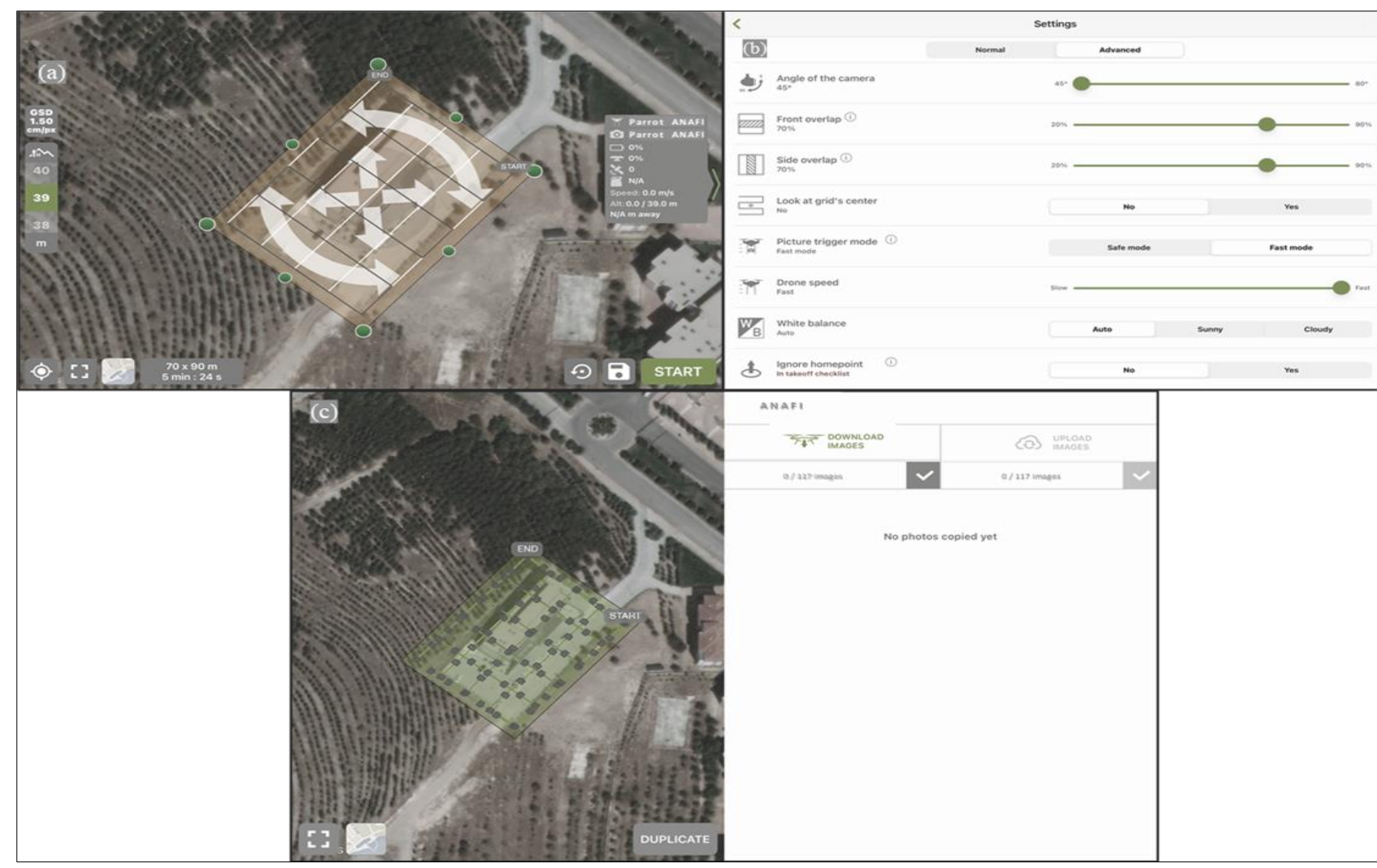

Figure 3. UAV Flight Planning Oblique Image Acquisition (A- Flight planning, B- Flight planning details, C- Postflight details)

\section{RESULTS}

The aerial images acquisition by the UAV flight and the GCPs coordinates obtained from the field by GNSS were imported to the UAV image processing software and evaluated. As the first step, the images were matched each other. A sparse cloud point was produced by finding the matching points in the common areas between this process step and the aerial images. In addition, together with the sparse point cloud, the camera's interior orientation parameters are automatically taken from the software library. Calibrating UAV cameras does not result in a huge increase in inaccuracy. Previous research shows that it would be appropriate to apply default camera parameters rather than calibrating the UAV Camera (Cramer et al., 2017; Przybilla et al., 2020). The camera's interior orientation parameters can be seen in the camera calibration report (Table 2).

Table 2. The camera's interior orientation parameters

\begin{tabular}{|l|l|l|l|l|l|l|l|l|l|l|l|l|l|}
\hline & Value (px.) & Error & $\mathrm{F}$ & $\mathrm{Cx}$ & $\mathrm{Cy}$ & $\mathrm{B}_{1}$ & $\mathrm{~B}_{2}$ & $\mathrm{~K}_{1}$ & $\mathrm{~K}_{2}$ & $\mathrm{~K}_{3}$ & $\mathrm{~K}_{4}$ & $\mathrm{P}_{1}$ & $\mathrm{P}_{2}$ \\
\hline $\mathrm{F}$ & 3683.58 & 0.15 & 1.00 & 0.04 & -0.63 & -0.24 & -0.07 & -0.20 & 0.24 & -0.21 & 0.19 & 0.05 & -0.60 \\
\hline $\mathrm{Cx}$ & -9.93684 & 0.15 & & 1.00 & -0.04 & 0.02 & 0.07 & 0.05 & -0.03 & 0.02 & -0.02 & 0.95 & -0.05 \\
\hline $\mathrm{Cy}$ & 12.9434 & 0.2 & & & 1.00 & -0.08 & 0.01 & -0.09 & 0.03 & -0.03 & 0.03 & -0.03 & 0.92 \\
\hline $\mathrm{B}_{1}$ & -0.0132771 & 0.039 & & & & 1.00 & 0.06 & -0.06 & 0.03 & -0.04 & 0.04 & 0.00 & 0.11 \\
\hline $\mathrm{B}_{2}$ & 0.779038 & 0.027 & & & & & 1.00 & -0.02 & -0.01 & 0.02 & -0.02 & 0.03 & 0.01 \\
\hline $\mathrm{K}_{1}$ & 0.0201138 & 0.00022 & & & & & & 1.00 & -0.97 & 0.92 & -0.87 & 0.03 & -0.09 \\
\hline $\mathrm{K}_{2}$ & -0.0784011 & 0.0011 & & & & & & & 1.00 & -0.99 & 0.96 & -0.02 & 0.04 \\
\hline $\mathrm{K}_{3}$ & 0.145407 & 0.0024 & & & & & & & & 1.00 & -0.99 & 0.01 & -0.04 \\
\hline $\mathrm{K}_{4}$ & -0.0903802 & 0.0016 & & & & & & & & & 1.00 & -0.00 & 0.04 \\
\hline $\mathrm{P}_{1}$ & -0.000301835 & $1.3 \times 10^{-5}$ & & & & & & & & & & 1.00 & -0.05 \\
\hline $\mathrm{P}_{2}$ & 0.00037642 & $1.4 \times 10^{-5}$ & & & & & & & & & & & 1.00 \\
\hline
\end{tabular}




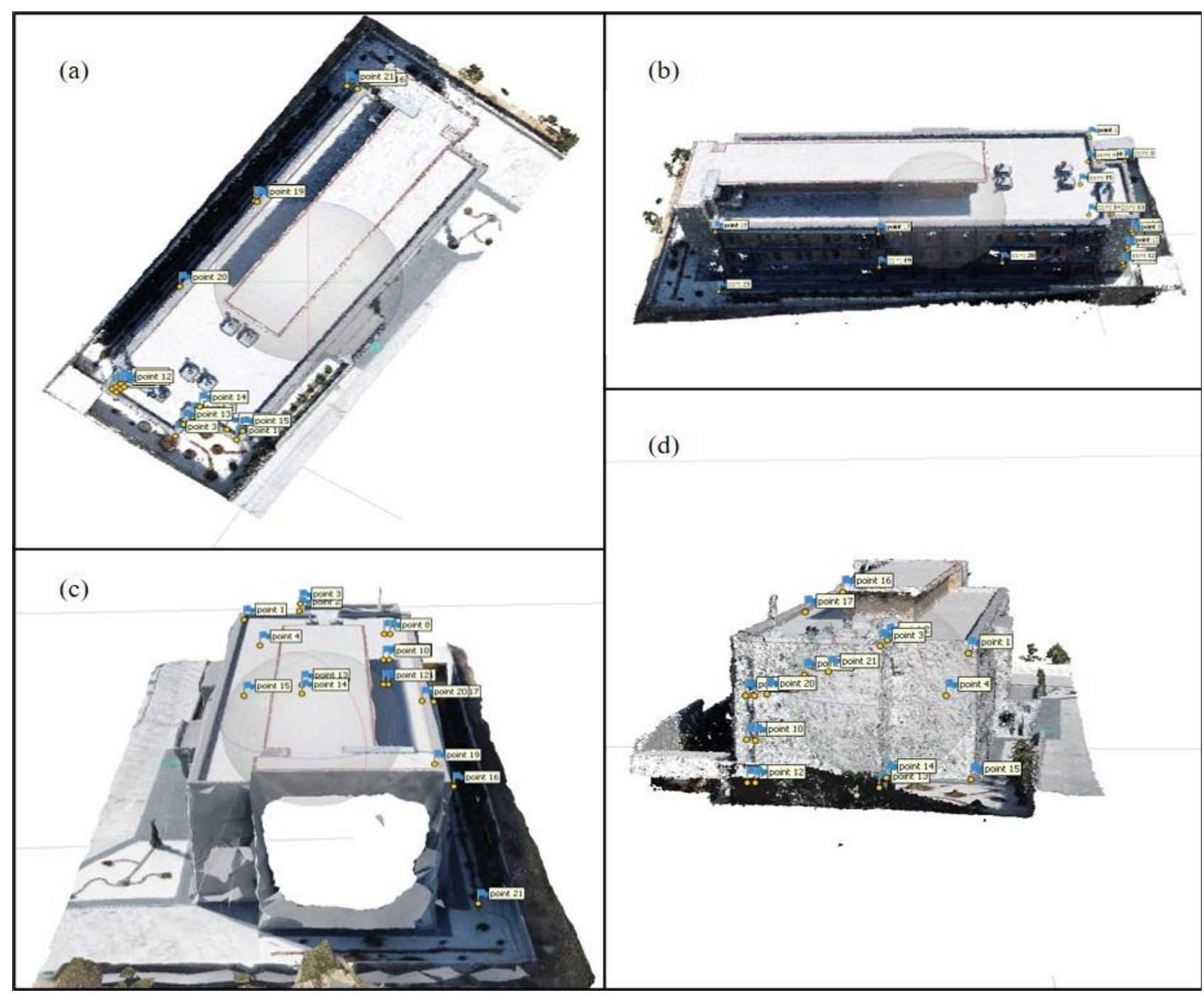

Figure 4. Dense point cloud data (A- Top View, B- Rear View, C- Right Side View, D- Left Side View)

As a next step, GCPs are defined for conversion and scaling to the field coordinate system. In the following step, a dense point cloud was created, in which the color information was also defined (Figure 4). The dense point cloud is based on the principle of compaction of optimal points by interpolation. After this step, where the software combines the depth information for each image acquisition point into a single set of dense points, the software creates the Triangulated Irregular Networks (TIN) by combining the dense point data with the color data (Figure 5). Then, the mesh model and texture model are produced using the TIN layer. The outcoming dense point clouds also form the basis for DEM and orthophoto.

The flights performed in the research caused some gaps in some parts of the 3D model of the building (especially the side facades and flat walls).
This problem is experienced for most of the objects that do not contain enough details in UAV photogrammetry. The point clouds (sparse and dense) generated by the software depend on the location of the acquisition centers of the images (appropriateness of the epipolar geometry) and the extraction of matchable detail in the images. When the error distributions of these produced points are reviewed, it is understood that the adjustment of coarsely faulted points is less than the mean faulty points. In addition, point distributions are proper to the aim of the study, except (right facade of the guesthouse) for a single facade.

As a scientific contribution, it can be said that oblique images can produce results such as rare images. This study shows that oblique images can provide a good alternative to situations where rare images are not likely to be very successful. 


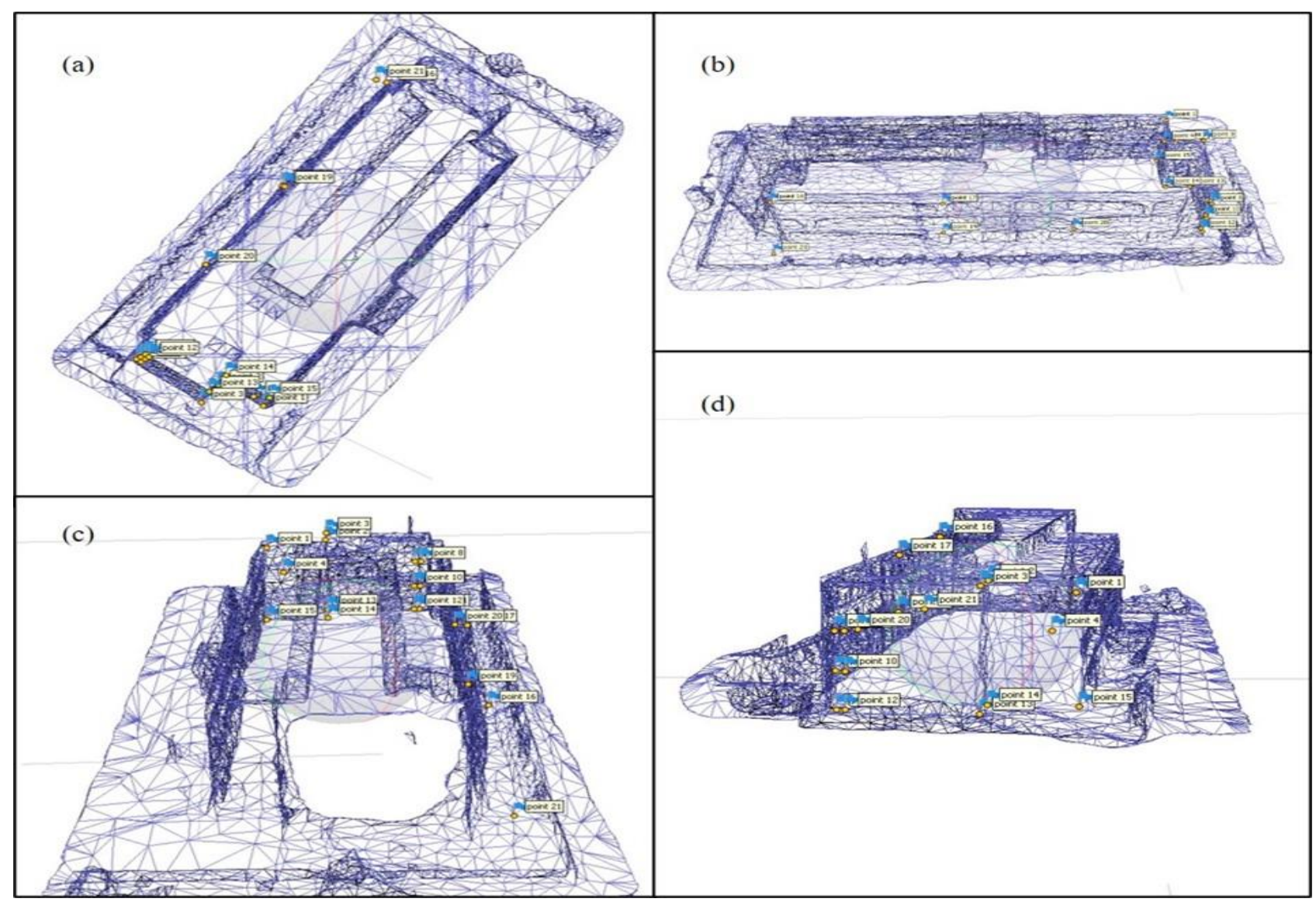

Figure 5. Triangulated Irregular Networks (A- Top View, B- Rear View, C- Right Side View, D- Left Side View)

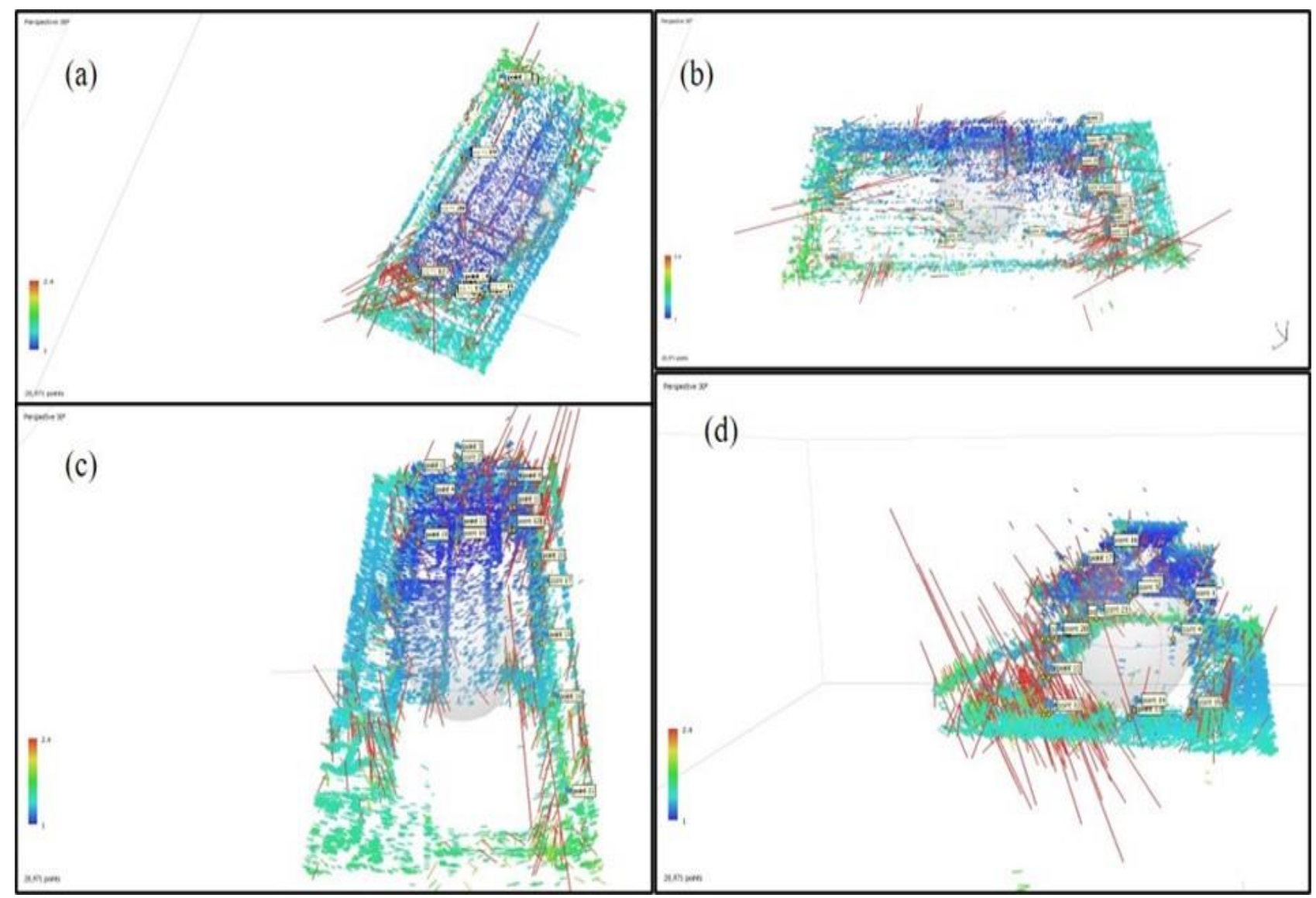

Figure 6. The error (pixel unit) of Points and their distribution to facades (A- Top View, B- Rear View, C- Right Side View, D- Left Side View) 


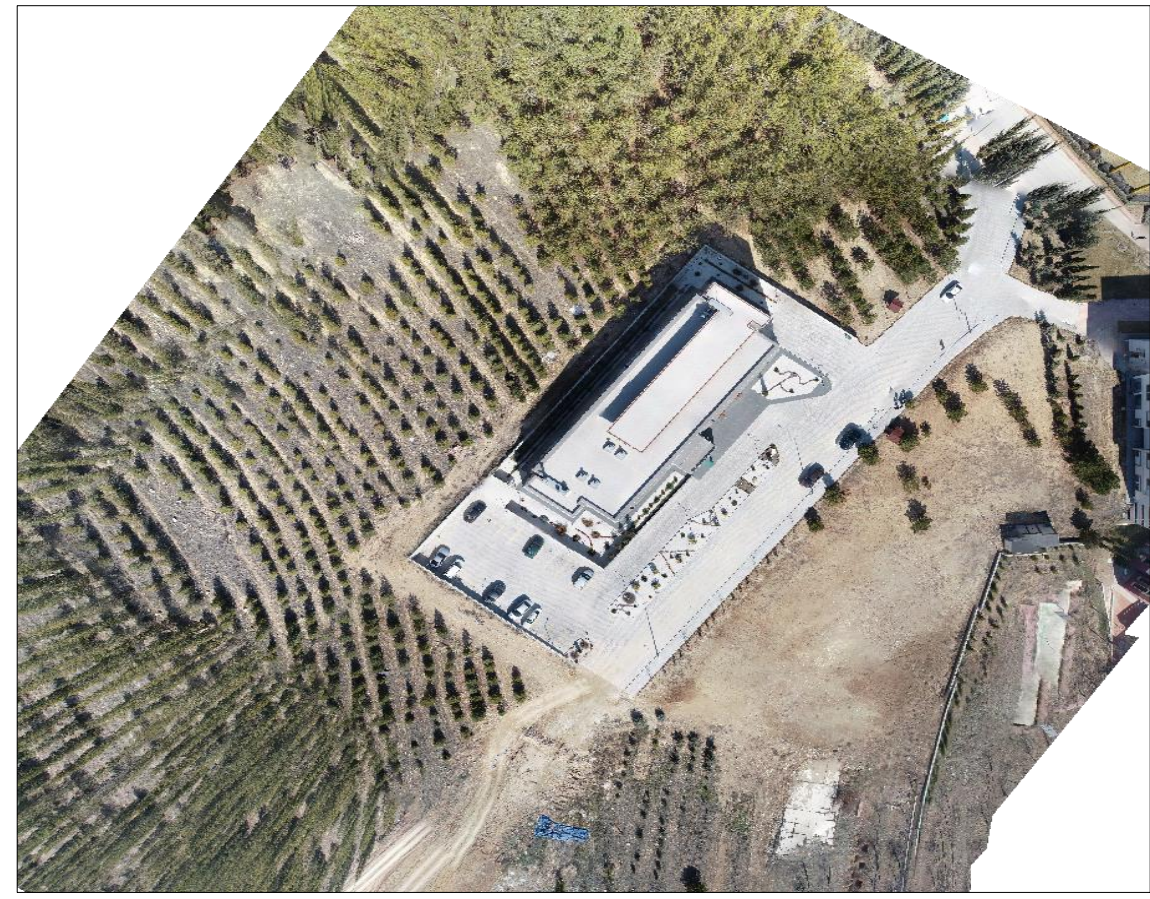

Figure 7. Orthomosaic

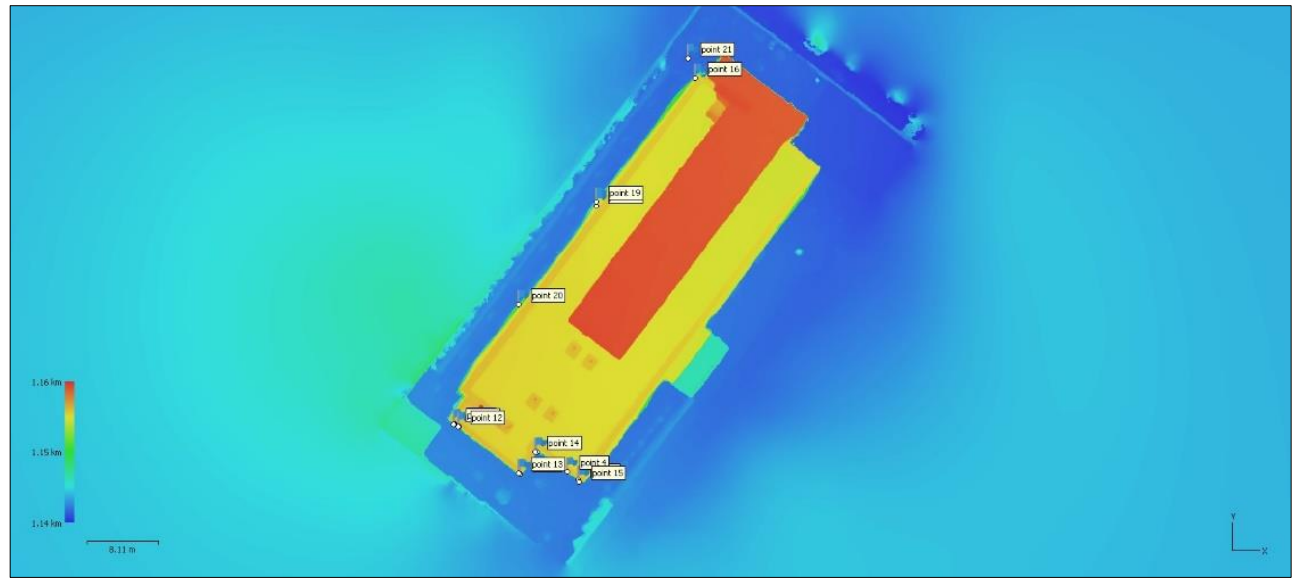

Figure 8. DEM

Oblique images were stuck together and obtained orthomosaic. This product is almost identical to the orthomosaic images taken with the nadir angle (Figure 7). In addition, DEM produced from oblique images allows a geometrically satisfactory result (Figure 8).

\section{CONCLUSIONS}

The orthomosaic and DEM obtained from oblique images are almost exactly the same as the orthomosaic and DEM produced from images taken in reality from the nadir angle. However, technical structures such as facade images, created TINs, meshes, and textures provide the results acquired with oblique images to be evaluated more efficiently. This research aimed to construct 3D models from oblique images and reduce the gaps in the outcomes acquired with the nadir direction 3D models.
It has been understood that almost all structural gaps in the final products can be closed by taking oblique images with the UAV. However, it has been determined that other methods are still needed for structures such as a plain wall without a pattern.

\section{Acknowledgement}

This work is supported by Konya Technical University Scientific Research Projects Coordinatorship with Project number 191005034.

\section{Author Contributions}

Hasan Bilgehan MAKINECI: Conceptualization, Data curation Methodology, Software, WritingOriginal draft preparation. Lütfiye KARASAKA: Conceptualization, Methodology, WritingReviewing and Editing. 


\section{Conflicts of Interest}

The authors declare no conflict of interest.

\section{REFERENCES}

Achille, C., Adami, A., Chiarini, S., Cremonesi, S., Fassi, F., Fregonese, L., \& Taffurelli, L. (2015). UAV-based photogrammetry and integrated technologies for architectural applicationsMethodological strategies for the after-quake survey of vertical structures in Mantua (Italy). Sensors, 15 (7), 15520-15539.

Aicardi, I., Chiabrando, F., Grasso, N., Lingua, A.M., Noardo, F., \& Spanò, A. (2016). UAV photogrammetry with oblique images: first analysis on data acquisition and processing. International Archives of the Photogrammetry, Remote Sensing \& Spatial Information Sciences, 41.

Cramer, M., Przybilla, H.J., \& Zurhorst, A. (2017). UAV cameras: Overview and geometric calibration benchmark. The International Archives of Photogrammetry, Remote Sensing and Spatial Information Sciences, 42, 85.

Erdönmez, M. (2018). Application of oblique photogrammetry with the help of unmanned aerial vehicles in structured areas (Master's thesis). Necmettin Erbakan University, Konya, Turkey (in Turkish).

Halıcı, E., \& Aydın, C.C. (2019). Eğik fotoğraflar ile 3 boyutlu kent modeli üretimi ve kullanım alanları. Türkiye Coğrafi Bilgi Sistemleri Dergisi, 1 (1), 14-26.

Jo, Y.H., \& Hong, S. (2019). Three-dimensional digital documentation of cultural heritage site based on the convergence of terrestrial laser scanning and unmanned aerial vehicle photogrammetry. ISPRS International Journal of Geo-Information, 8(2), 53.

Kun, M., \& Güler, Ö. (2019). İnsansız görüntüleme sistemleri ile elde edilen sayısal yüzey modellerinin mermer madenciliğinde kullanımı. Dokuz Eylül Üniversitesi Mühendislik Fakültesi Fen ve Mühendislik Dergisi, 21(63), 1005-1013.

Przybilla, H.J., Bäumker, M., Luhmann, T., Hastedt, H., \& Eilers, M. (2020). Interaction between direct georeferencing, control point configuration and camera self-calibration for
RTK-Based UAV photogrammetry. The International Archives of Photogrammetry, Remote Sensing and Spatial Information Sciences, 43, 485-492.

Rossi, P., Mancini, F., Dubbini, M., Mazzone, F., \& Capra, A. (2017). Combining nadir and oblique UAV imagery to reconstruct quarry topography: methodology and feasibility analysis. European Journal of Remote Sensing, 50 (1), 211-221.

Toprak, A.S., Polat, N., \& Uysal, M. (2019). 3D modeling of lion tombstones with UAV photogrammetry: a case study in ancient Phrygia (Turkey). Archaeological and Anthropological Sciences, 11(5), 1973-1976.

Tuncer, S., Çömert, R., \& Avdan, U. (2018). Tarihi yapilarin belgelenmesinde farkli yöntemlerle elde edilen verilerin entegrasyonu. VII. Uzaktan Algilama-Cbs Sempozyumu (UZAL-CBS 2018), 18-21 Eylül 2018, Eskişehir.

Uysal, M., Toprak, A.S., \& Polat, N. (2015). DEM generation with UAV Photogrammetry and accuracy analysis in Sahitler hill. Measurement, $73,539-543$.

Vacca, G., Dessì, A., \& Sacco, A. (2017). The use of nadir and oblique UAV images for building knowledge. ISPRS International Journal of GeoInformation, 6 (12), 393.

Valenti, R., \& Paternò, E. (2019). A comparison between TLS and UAV technologies for historical investigation. ISPRS-International Archives of the Photogrammetry, Remote Sensing and Spatial Information Sciences, 42(2), 739-745.

Yastikli, N., \& Özerdem Ö.Z. (2017). Architectural heritage documentation by using low cost UAV with fisheye lens: Otag-i Humayun in Istanbul as a case study. ISPRS Annals of the Photogrammetry, Remote Sensing and Spatial Information Sciences, 4, 415.

Zeybek, M., \& Kaya, A. (2020). Tarihi yığma kiliselerde hasarların fotogrametrik ölçme tekniğiyle incelenmesi: Artvin Tbeti kilisesi örneği. Geomatik, 5 (1), 47-57.

Url-1:

https://www.sony.com/en/SonyInfo/News/Pr ess/201411/14-112E/ (last accessed 27 June 2021) 